\title{
Placenta Percreta
}

National Cancer Institute

\section{Source}

National Cancer Institute. Placenta Percreta. NCI Thesaurus. Code C113386.

Histologically-confirmed deep attachment of the placenta into the myometrium and serosa. It may further extend into an adjacent organ such as the bladder. 